\title{
Engineering Education through eLearning technology in Spain
}

\author{
Juan Carlos Fernández Rodríguez ${ }^{1}$, José Javier Rainer Granados ${ }^{1}$, Fernando Miralles Muñoz ${ }^{2}$ \\ ${ }^{1}$ Bureau Veritas Centro Universitario, Madrid, Spain. \\ ${ }^{2}$ Universidad San Pablo CEU, Madrid, Spain
}

\begin{abstract}
Learning kind of education is stirring up all the disciplines in the academic circles, especially since it provides an access to educational areas that are uneasy and traditionally inperson, such as Engineering. Even though it had an outbreak in some of the most prestigious American universities, eLearning has being a reality in Spain for some years now, changing educational and teaching habits. To ensure a proper education is not an easy task with it comes to engineering fields, therefore this article shows an update on the works developed on this issue and the technologies they used. In this report it is given a perspective of the intimate relationship between the eLearning method of learning and the studies of Engineering in Spain, through the TIC development and the current educational legislation. In this regard, teaching examples are given on several subjects of different engineering studies, emphasizing the good results obtained in the abovementioned experiences. Below here is a evaluation on the results obtained in the analyzed studies.
\end{abstract}

Keywords - eLearning, engineering, competencies, evaluation.

\section{INTRODUCTION}

$\mathrm{R}$ OYAL Decree 1393/2007 establishes the new regulation on official university educations. Through this decree, the Spanish university system is integrated in the European Higher Education Area (EHEA). In accordance to this new model, there has been a major swift, going from a teaching model based in the transmission of knowledge directly from the professor, to a model based on acquiring different competencies and the alumni learning process. Engineering studies, both from a grade and postgraduate point of view, have not been an exception.

Concisely, a competency, in the engineering environment, refers to the activities the engineer must be able to perform, using the information, skills and tools required to accomplish his professional practice [1]. This way, an education based on competencies is referred basically to expected and visible performances, meaning analysis, synthesis and evaluation.

The necessary learning process is not oblivious to the present technological changes, the use of TIC has lead to a big leap in evolution of distance learning, creating the eLearning method of education. eLearning provides the opportunity to create virtual learning environments focused on the student, as EHEA demands. The aim of these virtual learning environments is to move the emphasis from the teaching to the learning [2].

These scenarios are characterized by being basically interactive, efficient, distributed and easily accessible. According Khan, quoted by Boneu [3], an ELearning scenario must consider eight facts: instructional design, educational model, technology, interface development, evaluation, management, support and use ethics. The platform in which the eLearning is developed is the software server responsible for the users management, courses management and communication services. These platforms are not isolated systems, given that they can rely on tools developed by third parties or on integrations developed by the designers or administrators.

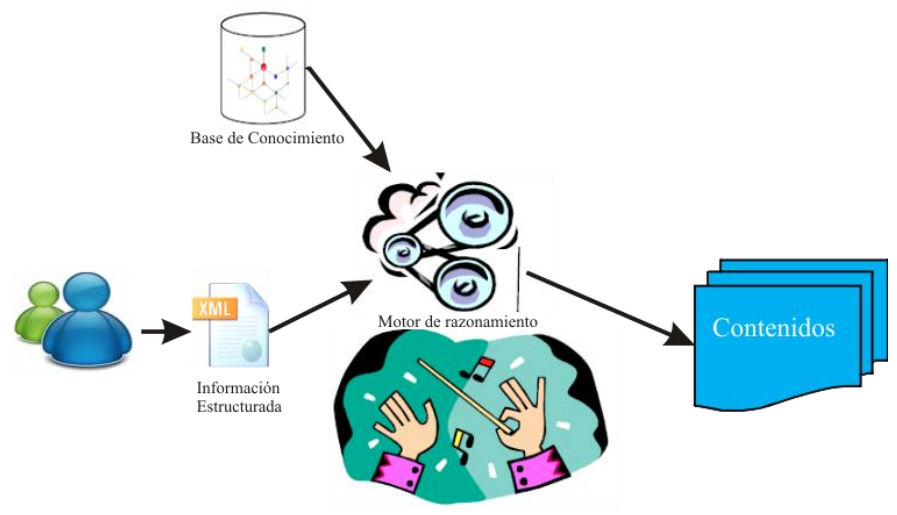

Fig.1. General Diagram of Contents Generation

eLearning can enhance some of the competencies that an engineer must develop, such as: identification, formulation and resolution of problems, the ability to design experiments or the ability to apply math, among others.

The specifications development, standard and tools regarding cognitive systems, ontologies and semantic maps are also helping in the formative systems enhacement.

In essence, the systems are based in showing some contents after receiving some request from the user. To this effect, the knowledge basis provides all the available information on this issue and some restrictions will select the definitive contents to show. Work on Intelligent Educational Systems (IESs) is traditionally divided into two main paradigms [4]: Intelligent Tutoring Systems (ITSs) [5] [6] and Adaptive Hypermedia Systems (AHSs) [7] [8]. 
According Caravantes and Galán [9], the essential part of the teaching-learning model is the educational domain, which is responsible for the stimuli generated toward the student to properly modify his cognitive state. All intelligent educational systems incorporate an educational domain that determines its scope and the process effectiveness. Usually the educational domain is divided into two parts: one represents the target knowledge of the learning process and is called domain model, and the other defines rules or procedures governing the process and is called the pedagogical/adaptive/operational model.

Teachers use the educational knowledge of a particular domain together with a meta-knowledge that encodes pedagogical skills for process controlling. This pedagogical knowledge represents instructional principles such as positive reinforcement, variability, action, etc., that facilitate the proper selection and sequencing of contents. It is a type of procedural knowledge based on Pedagogical Regulators (PRs) that controls the process, reading information from the emotional, characteristic and instructional domains. Common IESs implement an explicit pedagogical knowledge just as expert systems do using PRs called logical rules. However, there are other valid implicit representations such as neural networks, in which the PRs are called nodes, artificial neurons, and so on.

Learning content specifications like ADL-SCORM [10] or IMS-CC [11] are based on independent and interchangeable objects or packages that encode one or more ways to teachlearn something.

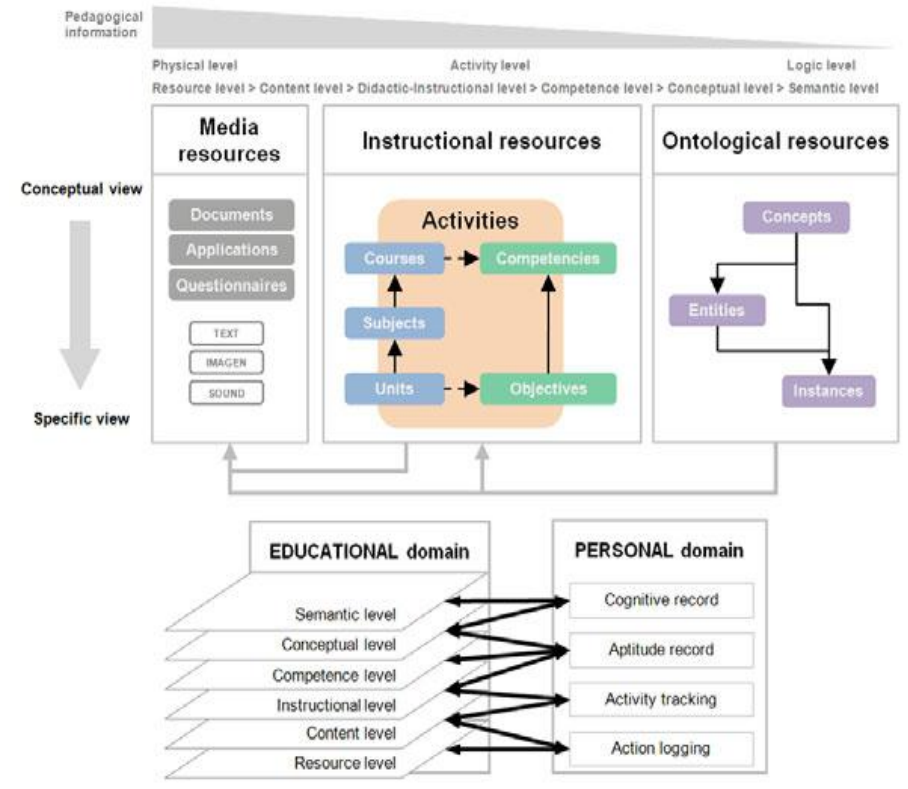

Fig.2. Levels of the educational knowledge representation [9].

Distance learning has usually made available to the student a set of continuous learning resources (documents, presentations, videos, animations and simulations) and discrete resources (texts, graphics, links and images) [12]. Resources are located at the lower material level of the educational knowledge structure to interact with the student to transfer knowledge. Educational resources are increasingly specified by soft links [13] that allow them to be searched, filtered and selected from large and dynamic repositories using metadata such as type (exercise, questionnaire, diagram, graph, table, text...), format, language, difficulty, etc. (see IEEE-LOM).

In this article, we will go through some of the experiences performed in the engineering area from the eLearning point of view, since just from the beginning eLearning and engineering have got along very well. Due to this connection, engineering learning becomes a higher quality learning, therefore it provides engineering a wider coverage regarding its education and extension [14].

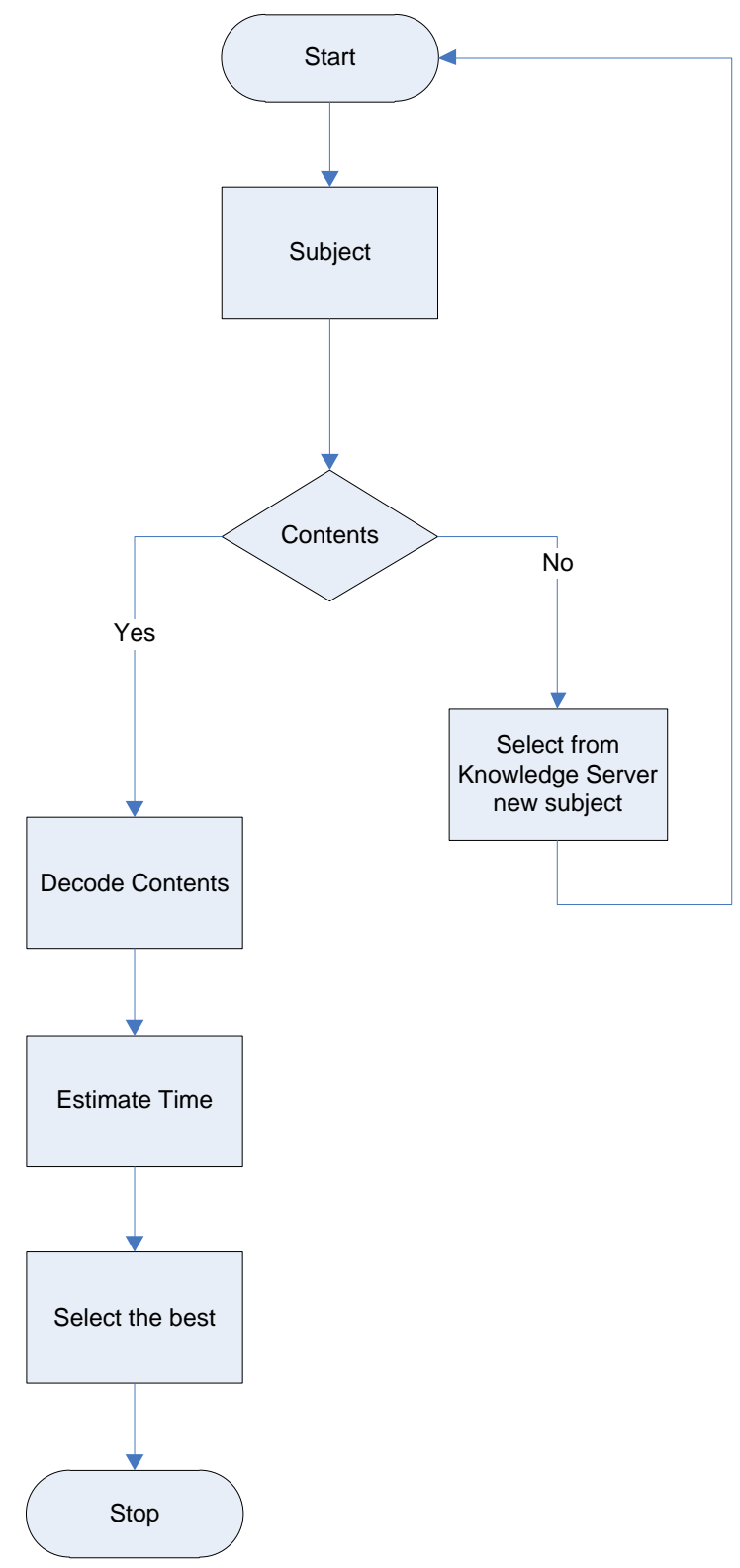

Fig. 3. General Diagram of Contents Management.

\section{II.ELEARNING AND ENGINEERING}

Engineering education has always been liked to attendance, especially because the help of a tutor easies the comprehension of the concepts and the assimilation of contents. It has been required the correct performance of the tools that integrate 
eLearning education in order to make sense out of engineering eLearning education. Therefore, the first works are somehow recent, as shown in some of the most important works, summarized below.

One of the first approaches in literature we can find was in 2000. In that year, there were already many American universities that would offer a wide range of courses with the eLearning teaching method [15], proving that, right from the start, eLearning was meant to become one of the strongest lines of high education.

Databases knowledge is one of the paramount subjects in the high courses of computer engineering. Back in 2006, and through the use of eLearning platforms, it was achieved not only to increase the motivations but to improve the academic results of the alumni in the Technical Engineering in Computer Managements and Systems in Gerona University [16]. The most relevant achievement of this study was the tool that auto corrects the exercises related to the subject. This tool allowed the professor to acknowledge the learning level of the students and realize their possible deficiencies. Also, there are significant gains for the students, since the passing rate increased around a $9 \%$. This increase might be caused by a sizeable boost of students that have taken on tutorial classes on the course.

In courses like "Databases" and "Business and Commercial Management Techniques" the auto correcting system had a great acceptance both within alumni and teachers, saving the later a significant work load: having to correct several exercises [17].

A very important aspect of this learning method is all that is related with the use and development of tools that will allow us to evaluate the assignments of the students in every subject automatically. In other words, a field that refers to the application of the different information and communication technologies in order to establish learning platforms and environments to make to evaluation of the alumni easier.

This way, the Computer Based Assessment (CBA) represents one of the eLearning technologies, distinguished by the automation of every teaching/learning feature of the student, integrating advanced functions held jointly, i.e., correcting databases structure diagrams and related consults [18]. With this CBA, there is an interaction between teacher and student all along the evaluation process. In this process, the turn in of the course exercises, its correction and the feedback generated is performed by the system automatically.

Put this into practice, CBA has been used in educational subjects of the science/technical area, mainly in test or multiple choice questions, with a limited scenarios feedback. The reason of these limitations is the disaffection toward these kinds of questions, since they can be perceived as distant and only acceptable in some low cognitive leveled tasks, which require fixed answers.

With this tool (CBA), the author scored better academic results and a higher satisfaction on the environment developed in students of the Databases subject of the Technical Computer Management Engineer of the Gerona University.

One of the tools that contributes to improve the learning process in multimedia environments are the Learning Objects, which are digital resources based on the Web, whose main feature is they can be used and reused to support the learning. A Learning Object (LO) is the minimal learning unit that has sense by itself, regardless of the context. Furthermore, it is a unit with an educational content and reusable in its digital format. Since this format must be standardized, it can be reused in different platforms, ensuring its reusability and usefulness [19]. Among these digital resources you can incorporate images, videos or pre-recorded audios, small text pieces, animations, little Web apps or even entire Web sites combining texts, images and other communication media.

One good example of the reusability and usefulness of the Learning Objects is the one performed on the Industrial Engineer School of Vigo University. Through this action, it was expected to encourage and motivate the engineering learning of the alumni, even though it can be conducted in any other discipline [20]. The authors designed a learning pill (very short course the summarizes the main concepts of the subject) in order to use it as a tool the students must use before the master lectures, but due to the specific features of the learning pills, they can be reached and used at any time and any place, thanks to their free access. The learning pill was effectively used by the whole alumni and it was verified that it was used worldwide.

The incorporation of multimedia technology and eLearning education has been applied equally to the Project Direction learning [21]. These authors instituted the eLearning technology in the "Projects" subject on the Industrial Engineering degree at Escuela Politécnica Superior de Ingeniería in Gijón. In order to achieve this, in this occasion it was selected a platform different from the traditional ones, such as Moodle. In this case, Microsoft Sharepoint was used, a specific project management tool, favoring the approach of the teacher's work towards the professional environment. The experience, besides enhancing the cooperative work between students, contributed to preparing the alumni towards the analysis, evaluation and alternatives choice, leading them to an educated decision making, something of paramount importance in their future engineering works. Nowadays, the eLearning method is widely spread in Projects Direction and Management and programs exist in most of the Spanish universities.

In engineering teaching, on-line methodologies have also been applied for evaluation and formation in generic competences. In the Technical Computer Engineering School of the Universidad Politécnica de Madrid it has been developed a competence approach for the "Telecommunications History" and "Telecommunications Policy for the Information Society" subjects, which were given through the Moodle platform. It is worth mentioning that the chosen teaching method was bLearning which, unlike eLearning, it combines online contents with in-person given contents. The results, evaluated through an online survey to the alumni, were highly satisfactory, pointing out several technical aspects, mainly the simplicity in the use of the Moodle platform [22].

The eLearning app can be used in any kind of subject, being the Logic subject of Computer Engineering both a particular 
and relevant example of application of this educational method [23]. In the Computer Engineering degree at UOC (Universidad Abierta de Cataluña), there is this Basic Logics subject. Said subject has very low performance and very high abandon ratings and by the application of eLearning with the idea of improving these rates in mind, eLearning was implemented. The results scored may be considered as discreet, being the reduction in abandoning rate just a 5\%, same as academic results improvement. It is important to point out that the measurement tools used to calculate these rates does not allow ensuring the reason of these changes is only the eLEarning based tool. The web sites of the tools have been developed using PHP for the server program, as well as HTML, CSS and Javascript. It is also worth mentioning that for the data lodging and abidance a MySQL database was used, granting an efficient session management.

The engineering laboratory practices have not been an exception on the eLearning educational method [24]. Particularly [25], the alumni were offered in their programming practices to use robots with eLearning method. In said practices, the student could book the robot for 30 minutes, and download and execute the program, being able to visualize it through an IP camera. Meanwhile, the web server was programmed to offer use statistics.

This project constantly seeks for the flexibility, therefore searches for a system design that is easily adaptable to any kind of experiment where the student used to utilize hardly reachable hardware, along making the high costs of an industrial robot profitable.

The main thing is that the learning curve is ascendant, even if it is the student who adjusts the intensity, leading to cases where the performance of the student behaves as shown in the following figure. The figure initials correspond to IN: I, initial phase of the course and $\mathrm{E}$, end of the course.

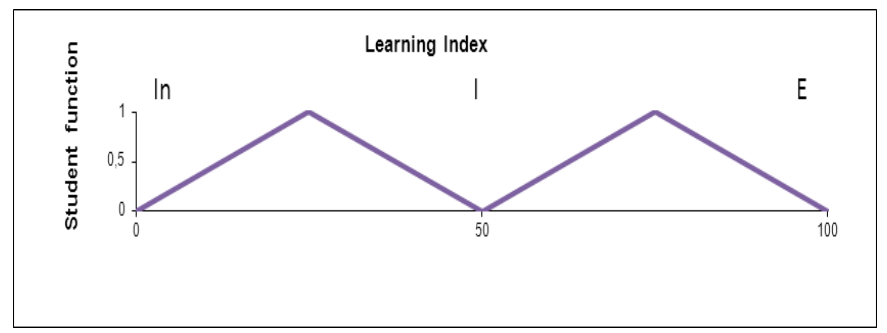

Fig. 4. Learning intensity along the course.

In a similar line [26], two traditional Systems and Automatic Engineering laboratories (three tanks control system and robot programming) of different universities have been transformed into two virtual and remote laboratories. This way, students can perform their lab exercises virtually, organized by an automatic booking system. The experience evaluation, gathered by a survey to the alumni, pointed out the achievement of an elevated satisfaction rate, existing among the students a high rate of motivation to use the technology in their learning activities.

\section{CONCLUSION}

In every experience analyzed in the present article is possible to detect the efficiency of the eLearning educational method in all the Engineering areas. In the abovementioned projects and their corresponding evaluations, is obvious the good results scored and the satisfaction of the students. The alumni feedback is very important for every learning method, through a satisfaction survey or test, but especially in this kind of method, since the student judges only the knowledge he has acquired, withdrawing any personal relationship he may have with his tutor, which can get even closer that in-person classes.

When it comes to eLearning education, the behavior of the system relies mainly in two factors: architecture and contents. In every cases previously analyzed, both factors are combined. The potential of these systems increases remarkably when Artificial Intelligence techniques are integrated, leading the system to a teacher-cognitive system combination that ensures not only the contents transmission but the proper choice of content within the wide knowledge database, supported by teaching techniques that permit an effective contents transmission as well as a certain knowledge acquisition.

Therefore it seems to be proof enough to state the validity of eLearning when it regards to engineering, as The American Accreditation Board for Engineering and Technology (ABET) claims [27]. Accordingly, not only the students score better results, but there is a possible chance to widely extend the education while cutting expenses, two important features when it comes to practice subjects to perform in laboratories.

However, there is a certain lack of more specific experiences, with a better educational design, and a lack of experiences that affect the paramount subjects of every engineering university title, both degree and masters. Besides, it would be convenient to expand the evaluation to teachers and apply a more severe criteria to evaluate de possible academic scores improvement, establishing the criteria required in order to ensure the students the correct acquisition of competencies.

Also it would be desirable a future research on the feelings of the student towards his presence and involvement in certain subjects and the improvements this might bring, being this an aspect where is pivotal the development and application of every multimedia technology available.

\section{REFERENCES}

[1] M. Duque, "Competencias, aprendizaje activo e indagación: un caso práctico en ingeniería". Revista de Educación en Ingeniería, 2, 2006, pp.7-18.

[2] J.E. Silva, "Diseño y moderación de entornos virtuales de aprendizaje". Barcelona: UOC, 2011.

[3] J.M. Boneu, "Plataformas abiertas de e-learning para el soporte de contenidos educativos abiertos". Revista de Universidad y Sociedad del Conocimiento (RUSC), (4) 1, 2007, pp. 36-47.

[4] A. Nicholas, B. Martin. "Merging adaptive hypermedia and intelligent tutoring systems using knowledge spaces". Adaptive Hypermedia (AH2008), 2008, pp. 426-430

[5] T. Murray. "Authoring Intelligent Tutoring Systems: An analysis of the state of the art". International Journal of Artificial Intelligence in Education, 98, 1999, pp. 98-129. 
[6] E. Wenger. "Artificial Intelligence and Tutoring Systems: Computational and Cognitive approaches to the communication of knowledge". San Francisco, USA, Morgan Kaufman, 1987.

[7] P. Dolog. "Designing Adaptive Web Applications". In SOFSEM 2008: Theory and Practice of Computer Science, pp. 23-33.

[8] P. Brusilovsky. "Methods and techniques of adaptative hypermedia". User Modeling and User Adapted Interaction, Special issue on adaptive hypertext and hypermedia, 6 (2-3), 1996,pp-87-129.

[9] A. Caravantes y R. Galán. "Generic educational knowledge for adaptive and cognuitive systems". Educational Technology \& Society, 14 (3), 2011, pp-252-266.

[10] ADL. "Sharable Content Object Reference Model (SCORM)". Retrieved June December, 11, 2012, from http://www.adlnet.gov/Technologies/scorm/default.aspx.2004.

[11] IMS. "Common Cartridge Specications". Retrieved December, 12, 2012, from http://www.imsglobal.org/cc. 2008.

[12] K. Verbert, E. Duval.. "Towards a Global Component Architecture for Learning Objects: A Comparative Analysis of Learning Object Content Models". World Conference on Educational Multimedia, Hypermedia and Telecommunications 2004, pp. 202-208.

[13] P Brusilovsky, N. Henze, N." Open corpus adaptive educational hypermedia. Adaptive Web 2007" (AW2007). pp. 671-696. Heidelberg: Springer.

[14] J. Bourne, D. Harris and F. Mayadas, (Janaury, 2005) "Online Engineering Education: Learning Anywhere, Anytime". Journal of Engineering Education. (94) 1, pp. 131-146 Avaible http://digitalcommons.olin.edu/facpub_2005/1.

[15] R. Ubell. "Engineers turn to e-Learning". IEEE Spectrum, 37, 2000, pp. 59-63.

[16] J. Soler, F. Prados, I. Boada and J. Pocho. "Utilización de una plataforma eLearning en la docencia de bases de datos". In Actas de las XII Jornadas de la Enseñanza Universitaria de la Informática, JENUI. Bilbao, 2006, pp. 581-586.

[17] J. Soler, I. Boada, F. Prados, J. Poch and F. Fabregat. "Experiencia docente en diseño de bases de datos con la ayuda de herramientas de eLearning" In Actas de las XII Jornadas de la Enseñanza Universitaria de la Informática, JENUI. Barcelona, pp. 63-70

[18] J. Soler. "Entorno virtual para el aprendizaje y la evaluación automática en bases de datos". Doctoral Thesis. University of Gerona, Spain, 2010.

[19] J.C. Fernández, J.J. Rainer and F. Miralles. "Aportaciones al diseño pedagógico de entornos tecnológicos eLearning”. Madrid, Lulu, 2012.

[20] R.Maceiras, A. Cancela and V. Goyanes. "Aplicación de Nuevas Tecnologías en la Docencia Universitaria”. Formación Universitaria (3) 1, 2010, pp. 21-26.

[21] J.M. Mesa, J.V. Álvarez, J.M. Villanueva and F.J. de Cos. "Actualización de métodos de enseñanza-aprendizaje en asignaturas de Dirección de Proyectos de Ingeniería”. Formación Universitaria (1) 4, 2008, pp. 23-28.

[22] R. Herradón, J. Blanco, A. Pérez and J.A. Sánchez. ). "Experiencias y metodologías "bLearning" para la formación y evaluación en competencias genéricas en Ingeniería". La Cuestión Universitaria, 3, 2009, pp. 33-45.

[23] M. Hertas, E. Mor and A. Guerrero-Roldan. "Herramienta de apoyo para el aprendizaje a distancia de la Lógica en Ingeniería Informática". Revista de Educación a Distancia, 24, 2010, pp. 1-10.

[24] L. Gomes and J. García-Zubia. "Advances on remote laboratories and eLearning experiences". Bilbao, Universidad de Deusto, 2007.

[25] Rosado, Muñoz-Marí and Magdalena. "Herramienta eLearning para la programación de robots mediante entorno web". Revista d'Innovació Educativa, 1, 2008, pp. 45-48.

[26] H. Vargas, J. Sánchez, C.A. Jara, F.A. Candelas, O. Reinoso and J.L. Díez. "Docencia en automática. Aplicación de las TIC a la realización de actividades prácticas a través de Internet". Revista Iberoamericana de Automática e Informática Industrial, (7) 1, 2010, pp. 35-45.

[27] ABET, Acreditation Board for Engineering and Technology. "Acreditation policy and procedure manual". USA, Engineering Accreditation Commission Publication, 2009.

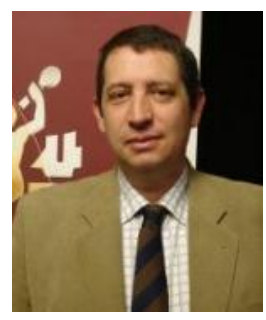

Juan Carlos Fernandez Rodríguez. He has been awarded a doctorate degree $(\mathrm{PhD})$ from the Universidad Complutense de Madrid UCM (Spain) and he is a bachelor of Philosophy and Sciences of Education from Universidad de Oviedo. At present he is Head of Studies and teacher in Bureau Veritas Centro Universitario. Actually he is investigating eLearning topics. He has great experience in the private sector and in the educational sector. He is author of several books and scientific articles. In addition, he has taken part as a speaker in congresses and symposiums.

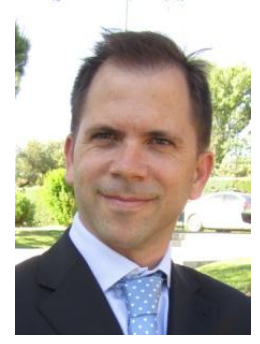

Javier Rainer (PhD). Received a PhD in Robotics and Automation from the Universidad Politécnica de Madrid, UPM (Spain) in 2011. He is Director of Research and Director of Engineering Area at Bureau Veritas Centro Universitario, and researcher at the Intelligent Control Group of the UPM. He is Industrial Engineer, from Málaga University. He has been co-author of published papers in several journals and recognized international conferences and symposiums. He received the best paper Award in IARIA Cognitive 2010.

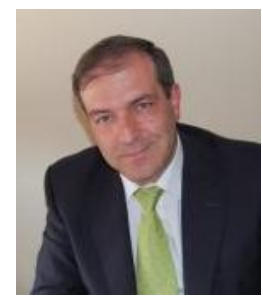

Fernando Miralles Muñoz.. Received a PhD in Phsicology from the Universidad Complutense de Madrid, UCM (Spain) in 2001. He is awarded honoraty doctoradtes from the Bircham International University since 2011. Currently combines his research with teaching at the University San Pablo CEU in Madrid 